\title{
Small-cell neuroendocrine carcinoma of the esophagus: an autopsy case report
}

Mariana Bellaguarda de Castro Sepulvidaa , Augusto Vieira Amaral ${ }^{a}$, Pompeu Tomé Ribeiro de Campos ${ }^{\mathrm{a}, \mathrm{b}}$, Carlos Osvaldo Teixeira ${ }^{\mathrm{a} b}$, Maria Aparecida Barone Teixeira

Sepulvida MBC, Amaral AV, Campos PTR, Teixeira CO, Teixeira MAB. Small-cell neuroendocrine carcinoma of the esophagus: an autopsy case report. Autopsy Case Rep [Internet]. 2014; 4(1): 15-19. http://dx.doi.org/10.4322/ acr.2014.003

\section{ABSTRACT}

Small-cell neuroendocrine carcinoma is a well-known aggressive neoplasia, which is usually associated with a poor prognosis. The lung is the most common primary site, but other organs may be involved, especially those of the digestive tract. The authors report the case of a 71-year-old Caucasian, male patient who was admitted because of congestive heart failure and loss of vision accompanied by right proptosis. Skull and sinuses computed tomography showed a tumoral mass involving the posterior region of the right eye, local bones, and paranasal sinuses. Because of severe hemodynamic instability, the patient died and no diagnostic investigation could be performed. Autopsy findings revealed small-cell neuroendocrine carcinoma of the esophagus and metastases to the posterior region of the right ocular globe, which affected the sinuses, the muscles of the ocular region, the orbit bones, the skull, the meninges and the brain, plus the liver, adrenal glands, and the pericardium. This case called the author's attention to the extent of the metastatic disease in a patient who was firstly interpreted as presenting solely with congestive heart failure. The autopsy findings substantially aid the understanding of the immediate cause of death.

Keywords: Carcinoma, Squamous Cell; Neuroendocrine Cells; Carcinoma, Small Cell; Esophagus; Autopsy.

\section{INTRODUCTION}

Small cell carcinoma (SCC) is a poor differentiated neuroendocrine carcinoma, which frequently involves the lung. However, its extra pulmonary origin represents $2.5-5.9 \%$ of all cases, represented by gastrointestinal $(\mathrm{Gl})$ and genitourinary systems, plus skin and thymus involvement. ${ }^{1-6}$. Among the GI viscera, the esophagus is the most commonly involved, although this histological tumor type represents only $0.4-3.1 \%$ of all esophageal neoplasms. ${ }^{1}$

Besides environmental factors, genetic alterations have a marked role in the pathophysiology of this tumor, ${ }^{7}$ independently of the primary site.

\footnotetext{
${ }^{a}$ Anatomo-clinical Correlation Study Group (GECAC) - Faculdade de Medicina - Pontifícia Universidade Católica de Campinas - Campinas/SP - Brazil.

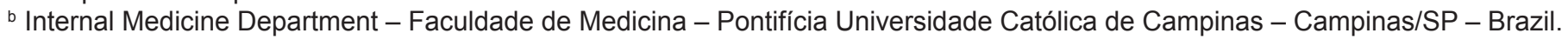


Among the environmental factors, smoking and alcohol consumption are the main components. .,6,8 $^{2}$ Men are 1.3-3.2 times more affected than women mainly in the fifth or sixth decade of life. The initial symptoms are usually unremarkable, and even the clinical features of advanced disease are non-specific, like weight loss and instability of previous chronic diseases. Local symptoms, such as dysphagia and retrosternal pain, are associated with esophageal wall infiltration or occlusion of the esophageal lumen, which are associated with the worse prognosis in this setting. ${ }^{1,6,8-10}$

Pathological characteristics of SCC are the same, regardless of the primary site. The neoplastic cells are small, polymorphic, with scanty cytoplasm, and hyperchromatic nuclei, and they present a trabecular growth. ${ }^{2,3,8,9,11}$ The positivity for specific epithelial markers, such as epithelial membrane antigen (EMA), clonal cytokeratin (AE1/AE3), and cytokeratin 8 (CK8) identify these cells as being of epithelial origin. ${ }^{2,9,11}$ The neuroendocrine lineage is identified by other markers, such as neuron-specific enolase (NSE), synaptophysin (SyN), chromogranin A $(\mathrm{CgA})$, and a neural cell adhesion molecule (CD56). About $36 \%$ of the esophageal SCC show histological heterogeneity, presenting endocrine and squamous lineages within the same tumor..$^{9,11}$

\section{CASE REPORT}

A 71-year-old Caucasian male patient sought medical care complaining of a 4-month history of exertion dyspnea and edema of the lower limbs. His past medical history included hypertension and congestive heart failure, and although he had been abstinent for 1 year, he had previously smoked 75 packs/year. On physical examination he was hypotensive and cyanotic; his pulse was arrhythmic; he had edema of the lower limbs; he had bulging jugular veins when in the supine position; there were rales in the lower two-thirds of both lungs; and tender hepatomegaly was present. The electrocardiogram showed atrial fibrillation, and the echodopplercardiogram estimated the left ventricle ejection fraction of $63 \%$ (Teicholz), eccentric left ventricular hypertrophy, marked mitral insufficiency, and a left atrium of $85 \mathrm{~mm}$. Pulmonary systolic pressure was estimated at $62 \mathrm{mmHg}$ with marked tricuspid valve insufficiency. There were no valvular morphological abnormalities. He was hospitalized with the diagnosis of hypertensive cardiomyopathy and cor pulmonale.
He also complained of vision loss for 2 months accompanied by protrusion of the right eye globe. The ophthalmologic examination in the right eye revealed marked corneal deepithelization and edema, ocular protrusion, the absence of photomotor and consensual reflexes, and low visual acuity. The left eye was normal. Brain computed tomography and cranial magnetic resonance imaging (MRI) confirmed the presence of a neoplastic lesion infiltrating the paranasal sinuses and the frontal encephalic lobe (Figure 1). A tumoral biopsy was scheduled, but the patient died before the procedure could be done because of a refractory cardiogenic shock.

Autopsy findings included marked cardiomegaly with four-chamber dilation; the interventricular septum measured $18 \mathrm{~mm}$, and the ventricular wall (posterior, anterior, and lateral) measured $15 \mathrm{~mm}$. Radiological findings were confirmed at autopsy as a metastatic lesion most probably from an epithelial neoplasm of the esophagus. A $2 \mathrm{~cm}$ wide ulcerated lesion was found in the middle third and other lesion with a vegetating appearance measuring $1 \mathrm{~cm}$ in the upper third of the esophagus (Figure 2) The tumor infiltrated the submucosa, muscular (Figure 3 and $4 \mathrm{~A}$ ), and adventitia layers and adhered to the paraesophageal structures mainly at the esophageal-ulcerated lesion.

The histological examination showed a smallcell neuroendocrine carcinoma of the esophagus, since AE1/AE3 positive and synaptophysin (Figure 4B) were positive.

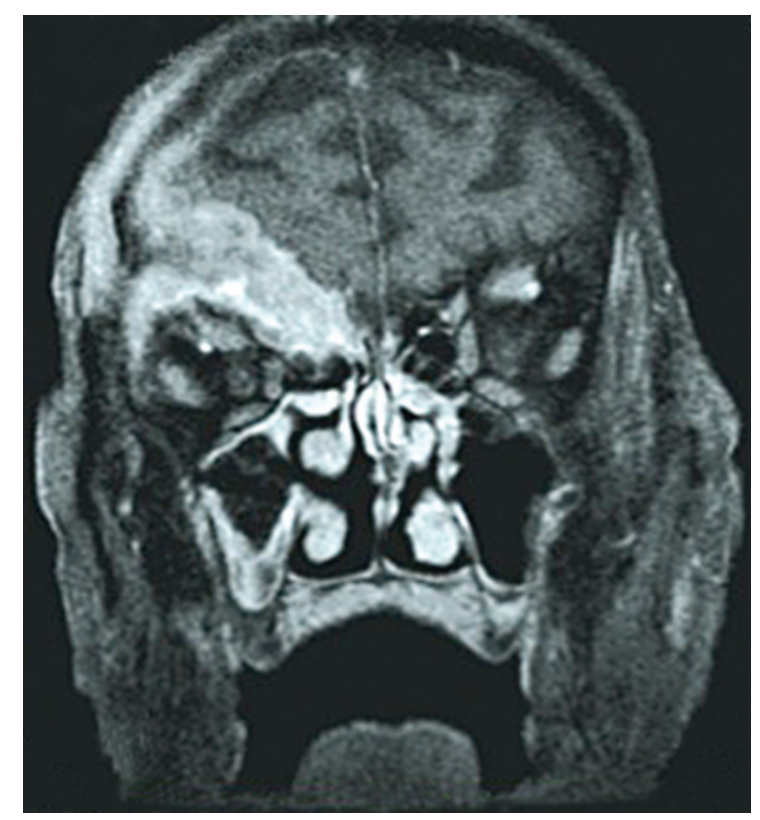

Figure 1 - Cranial MRI showing the retroocular metastatic lesion. 


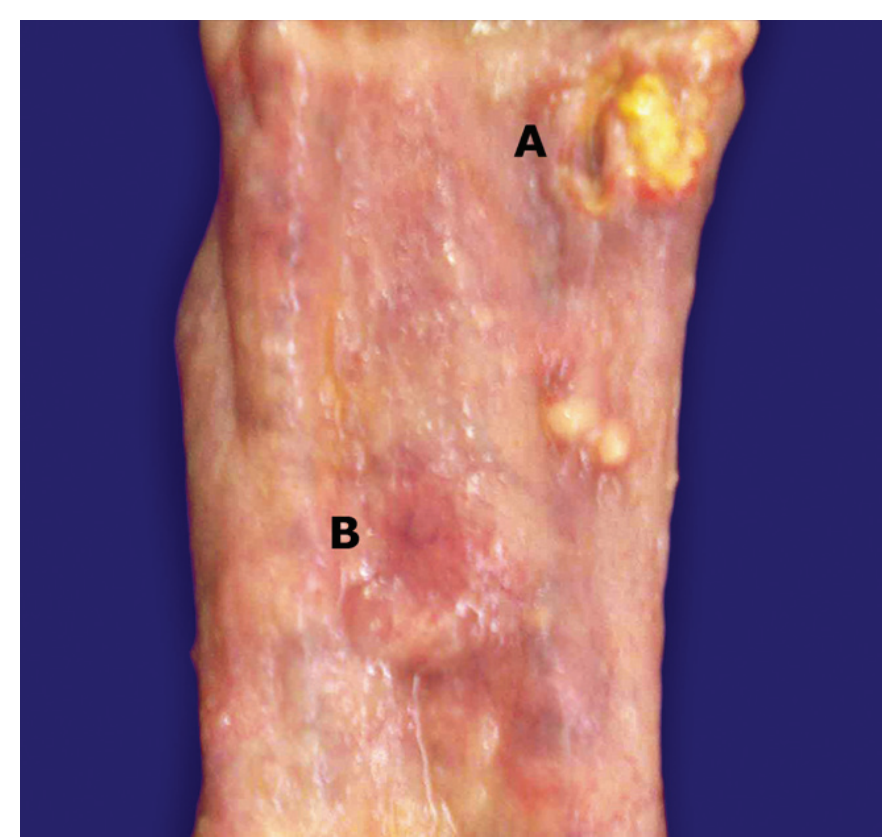

Figure 2-Gross view of the esophagus showing a vegetating pattern lesion $(A)$ and an ulcerated lesion (B) at the proximal and middle thirds, respectively.
Metastatic involvement was found in the paranasal sinuses, the muscles around the right eye, the orbital bones (Figure 5), the meninges, the right frontal lobe, the liver, the adrenal glands, and the pericardium.

\section{DISCUSSION}

In 1952, the Pathology Institute of Belfast (Northern Ireland) first reported two cases of this neoplasia among 9,000 autopsies. ${ }^{1,12}$ Since then, around 350 cases of esophageal SCC have been published, showing its aggressive behavior and the challenging diagnosis in the great majority of cases, revealing the difficulty in establishing the best therapeutic option. ${ }^{1,9}$

In our case, diagnosis was missed due to the absence of specific symptoms, according to the literature. ${ }^{1-16}$ It is most likely that interleukins 1 and

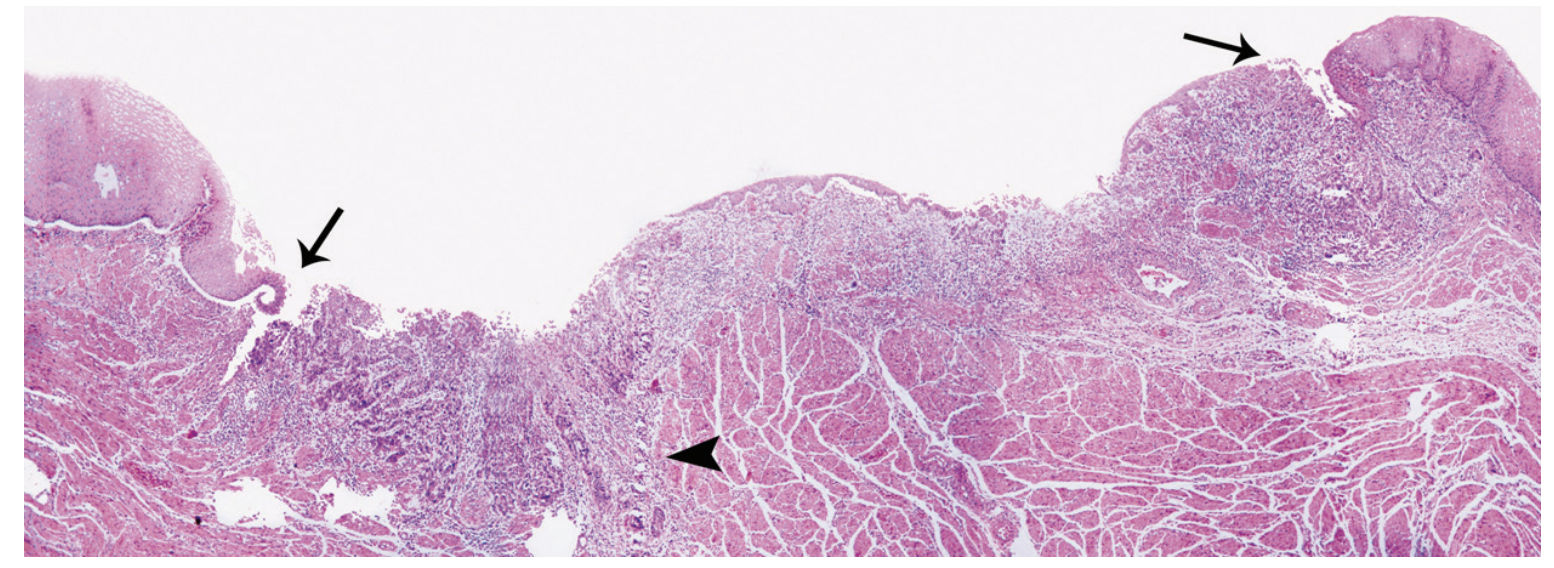

Figure 3 - Photomicrography of the esophagus showing ulcerated lesions (arrows) with inflammatory infiltrate (arrowhead) involving the submucosa and muscular layers (HE, 40X).

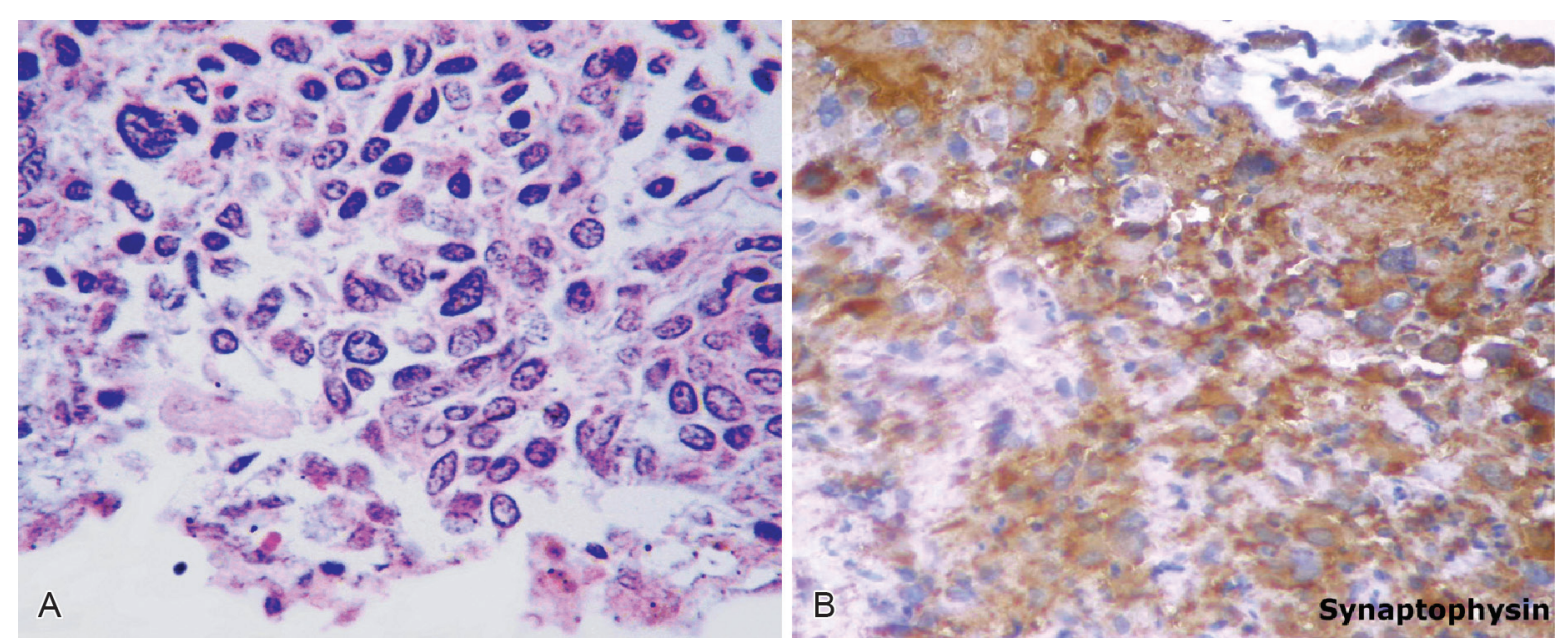

Figure 4 - Photomicrography of the esophageal ulcerated lesion showing in A - Neoplastic cells with hyperchromatic nuclei, "salt-and-pepper" chromatin and scant cytoplasm. (HE, 400X), and in B - positivity for synaptophysin,(400X). 

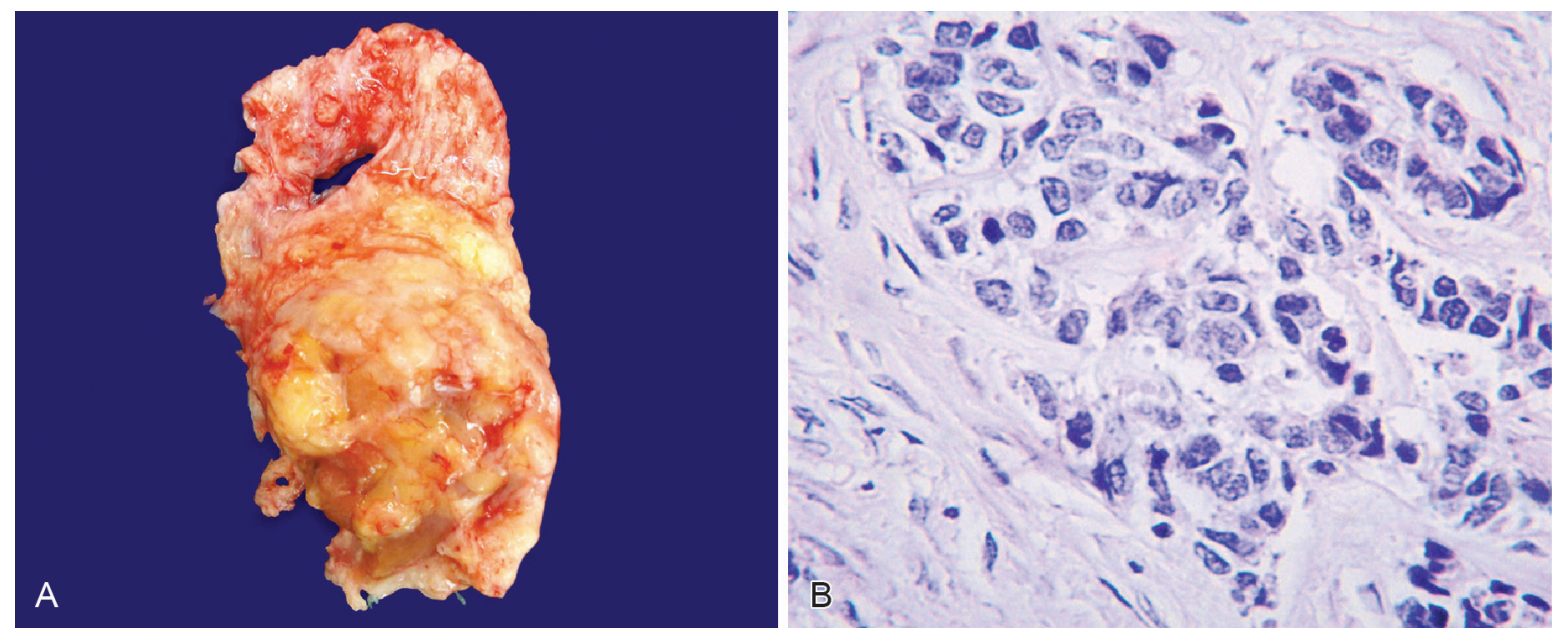

Figure 5 - A - Gross view of the retroocular mass involving the orbit muscles. B - Photomicrography of the retroocular mass showing neoplastic cells with the same pattern as the esophageal lesion (HE, 400X).

6 , as well as the tumoral necrosis factor, ${ }^{16}$ may have contributed to the severe hemodynamic instability of the patient, which prevented any further diagnostic approach.

Neuroendocrine carcinomas with retroocular metastasis are scarce in the literature. Among the patients with this diagnosis, the main described symptoms are: diplopia (48\%), local pain $(42 \%)$, and loss of vision (30\%). The signs at presentation are: proptosis $(63 \%)$, strabismus $(62 \%)$, and loss of vision (30\%). ${ }^{15}$ Except for the pain, the patient of the case reported herein presented the main described signs and symptoms.

However, our patient did not present signs of carcinoid syndrome or paraneoplastic manifestations, since the latter is represented by three reports of esophageal SCC presenting sensory and motor neuropathy, inappropriate antidiuretic hormone secretion syndrome, and hypercalcemia. ${ }^{1,5,10,13}$ We did not attribute the heart failure to a possible carcinoid syndrome in our patient, since other manifestations of this syndrome were lacking, such as flushing, diarrhea, or bronchospasm. The carcinoid heart is characterized by an endocardial fibrous deposition, mainly at the outflow of the right cardiac chambers accompanied by valvular morphological derangement and dysfunction. ${ }^{17}$

On gross examination, esophageal SCC may present as infiltrating, polypoid, or ulcerated lesions ${ }^{10}$ mainly localized in the middle or lower third of the organ. .,6,8 $^{1,8}$ The case reported herein presented an ulcerating lesion on the middle third, and another polypoid in the upper third, which is the site in 4-6\% of all described esophageal SCCs., ${ }^{4,8,14}$ The tumor in this topography usually does not cause dysphagia. This patient already presented, at admission, an advanced metastatic disease to well-known sites such as the liver and bones, but, in contrast to the majority of cases, the lungs were not involved. Surprisingly, metastases were found in previously unreported sites for this tumor, namely: the frontal lobe, the meninges, the skull, the paranasal sinuses, the eye and adjacent structures, the adrenal glands, and the pericardium. . $^{1,5,6,8,14,15}$

This neoplasia presents an overall survival rate that ranges between 3.1 and 7.5 months after the diagnosis. ${ }^{1,2,8,9}$ Metastatic disease at diagnosis is found in $31-90 \%$ of the cases. ${ }^{6}$

The World Health Organization classifies all the neuroendocrine neoplasms in three categories, according to their morphology, independently of the primary site; for example, well-differentiated neuroendocrine tumors with low malignant potential, well-differentiated neuroendocrine carcinoma (which are more aggressive with metastatic potential) and poorly-differentiated neuroendocrine carcinomas (which are high grade malignancies with poor prognosis). ${ }^{7}$

The anatomopathological and immunohistochemical criteria for the diagnosis of SCC are the same regardless of the primary site, but for the GI tract, the immunohistochemical markers CK8, SyN, NSE, and CD56 show more than 90\% accuracy. ${ }^{3,8,9,11}$ In our case, only SyN and AE1/AE3 were tested; therefore, we could not differentiate pure- or mixed-cell lineages in the tumor.

\section{CONCLUSION}

Small-cell neuroendocrine carcinoma is an aggressive neoplasm with poor prognosis, 
regardless the primary site. Its rarity and late clinical manifestation, mostly represented by metastatic disease or systemic symptoms delay the diagnosis and treatment.

In our case, the diagnosis wasn't totally established in life due to the unusual retro-ocular metastatic presentation. Inflammatory factors related to the tumor probably aggravated the heart failure.

This case demonstrates the importance of the autopsy for didactic and diagnostic purposes.

\section{REFERENCES}

1. Wang SY, Mao WM, Du XH, Xu YP, Zhang SZ. The 2002 AJCC TNM classification is a better predictor of primary small cell esophageal carcinoma outcome than the VALSG staging system. Chin J Cancer. 2013;32:342-52.

2. Henry MACA, Lerco MM, Oliveira WK, et al. Carcinoma de pequenas células do esôfago: estudo clínico patológico de dois casos. ABCD Arq Bras Cir Dig. 2008;21:3840. Portuguese. http://dx.doi.org/10.1590/S010267202008000100008

3. Yun JP, Zhang MF, Hou JH, et al. Primary small cell carcinoma of the esophagus: clinicopathological and immunohistochemical features of 21 cases. BMC Cancer. 2007;7:38. http://dx.doi.org/10.1186/1471-2407-7-38

4. Casas F, Ferrer F, Farrús B, Casals J, Biete A. Primary small cell carcinoma of the esophagus: a review of the literature with emphasis on therapy and prognosis. Cancer.1997;80:1366-72. http://dx.doi.org/10.1002/ (SICI)1097-0142(19971015)80:8<1366::AIDCNCR2>3.0.CO;2-D

5. Rekhtman N. Neuroendocrine tumors of the lung: an update. Arch Pathol Lab Med. 2010;134:1628-38.

6. Vos B, Rozema T, Miller RC, et al. Small cell carcinoma of the esophagus: a multicentre Rare Cancer Network study. Dis Esophagus. 2011;24:258-64. http://dx.doi.org/10.1111/ j.1442-2050.2010.01133.x
7. Dias AR, Sallum RAA, Zalc N, Ctenas BB, Ribeiro U Jr, Cecconello I. Squamous cell carcinoma and neuroendocrine carcinoma colliding in the esophagus. Clinics (Sao Paulo). 2010;65:114-7. http://dx.doi.org/10.1590/S180759322010000100018

8. Coral RP, Hartmann A, Mastalir FP, Mastalir ET. Small cell carcinoma of the esophagus. ABCD Arq Bras Cir Dig. 2007;20:216-8. http://dx.doi.org/10.1590/S010267202007000300017

9. Schlittler LA, Lazaretti NS, Villaroel RU, Klitzke S, Dallagasperina VW. Carcinoma de pequenas células do esôfago: apresentação de dois casos. J Port Gastrenterol. 2011;18:243-6. Portuguese.

10. Sabanathan S, Graham GP, Salama FD. Primary oat cell carcinoma of the oesophagus. Thorax. 1986;41:318-21. http://dx.doi.org/10.1136/thx.41.4.318

11. Li AF-Y, Li AC-H, Hsu C-Y, Li WY, Hsu HS, Chen JY. Small cell carcinomas in gastrointestinal tract: Immunohistochemical and clinicopathological features. J Clin Pathol. 2010;63:6205. http://dx.doi.org/10.1136/jcp.2010.077024

12. McKeown F. Oat-cell carcinoma of the œsophagus. J Pathol. 1952;64:889-91. http://dx.doi.org/10.1002/path.1700640420

13. Shimoda T, Koizumi W, Tanabe S, et al. Small-cell carcinoma of the esophagus associated with a paraneoplastic neurological syndrome: a case report documenting a complete response. Jpn J Clin Oncol. 2006;36:109-12. http://dx.doi. org/10.1093/jjco/hyi241

14. Souza HP, Alves JM, Pandolfo G. Carcinoma de pequenas células do esôfago. Rev Col Bras Cir. 1998;25:2902. Portuguese. http://dx.doi.org/10.1590/S010069911998000400015

15. Peixoto RDA, Lim HJ, Cheung WY. Neuroendocrine tumor metastatic to the orbit treated with radiotherapy. World J Gastrointest Oncol. 2013;5:177-80. http://dx.doi.org/10.4251/ wjgo.v5.i8.177

16. Silva AC, Alves RC, Pinheiro LS. As implicações da caquexia no câncer. e-Scientia. 2012;5:49-56. Portuguese.

17. Amador P, Mendes L, Gonçalves S, et al. [Carcinoid tumors: echocardiographic contribution to the diagnosis]. Acta Med Port. 2011;24:843-8. PMID: 22525639 Portuguese.

\section{Conflict of interest: None}

Submitted on: $10^{\text {th }}$ December 2013

Accepted on: $15^{\text {th }}$ March 2013

Correspondence: Mariana Bellaguarda de Castro Sepulvida

Rua Espírito Santo, 1136 - Cerâmica - São Caetano do Sul - São Paulo/SP - Brazil

CEP: 09530-701 - Phone: +55 (19) 99341-5399

E-mail: mbellaguardasepulvida@yahoo.com.br 